\title{
Flujo Genital
}

\section{Correlato de la Sociedad de Ginecología y Obstetricia del Atlántico*}

\author{
Dr. Eduardo Acosta Bendek \\ Dr. Julio Duva Palacio
}

\author{
Dr. Néstor Vásquez Macías \\ Dr. Carlos Iriarte
}

Definimos con el nombre de flujo genital toda secreción anormal y permanente, de carácter no hemático, de cualquier sector genital y que es la expresión de un estado anormal o patológico (1). Llamamos flujo fisiológico, o leucorea, aquel que está relacionado con el ciclo menstrual normal y que es el resultado de un proceso fisiológico funcional, $y$ de ocurrencia más frecuente en mujeres que presentan alteraciones de tipo psicovegetativo; este flujo llamado leucorrea presenta unas características muy definidas: color blanco mucoso, formado por una abundante descamación epitelial y moco de orígen úterovaginal, con un $\mathrm{pH}$ de 3.8 a 4.5, presencia de grandes cantidades de

* Trabajo elaborado en el Hospital Universitario Metropolitano.

* Decano y profesor de Gineco-obstetricia. Facultad de Medicina Universidad Metropolitana.

** Jefe Departamento de Gineco-obstetricia del Hospital Universitario Metropolitano y profesor Universidad Metropolitana.

**** Profesor de Gineco-obstetricia. Universidad Metropolitana.

**** Instructor Universidad Metropolitana. bacilos de Döderlein y escasas bacterias $(2,3,4)$; este cuadro fue lo que Schroder clasificó como primer grado de pureza vaginal, pureza condicionada por la presencia de los bacilos de Döderlein responsables de mecanismos de autodepuración vaginal. Cuando se rompe el equilibrio funcional del medio vaginal se presentan una serie de síntomas y signos en la parte baja del aparato genital, que se manifiestan por la presencia de un flujo de caracteres multifacéticos, asociados unas veces a vulvovaginitis con prurito, ardor, disuria y dolor pélvico $(5,6)$, síntomas que vienen a constituir una de las consultas más frecuentes en la gineco-obstetricia actual. La observación macroscópica del contenido vaginal o de su epitelio, no permite ni al más experimentado ginecobstetra formular un diagnóstico del tipo de flujo por su sola característica; así encontramos cómo el flujo producido por tricomonas, de aspecto verde, espumoso, algunas veces o de color grisoso otras, puede ser también producido por el Corynebacterium vaginalis (7), por el Micrococos gazógenes alcalescens y por el Proteus vulgaris; fenómeno semejante sucede también con otros tipos de flujos específicos. Por lo tanto para hacer un diagnóstico clínico del flujo genital es aconsejable hacer una anamnesis de la paciente, relacionada con en- 
fermedades recientes, tratamientos con drogas en el momento de la consulta, edad de la paciente; observamos en la práctica que en una niña o en una mujer menopáusica es más frecuente el flujo por Candidiasis o por bacterias inesnecíficas. La misma situación la observamos en pacientes diabéticas mal controladas, en las usuarias de contraceptivos hormonales, en las de tratamiento con antibióticos de amplio espectro, de corticoides y de citostáticos; en pacientes de vida sexual activa, especialmente las meretrices, son más frecuentes los flujos causados por Neisseria gonorrea, Tricomonas vaginalis, Corynebacterium vaginalis y Cándida albicans, en las que la transmisión de tipo venéreo desempeña un papel principal. Además de las consideraciones anteriores, el médico actualmente cuenta con una serie de procedimientos de laboratorio, ćomo son el examen en fresco, el frotis extendido de Gram y los medios de cultivos selectivos, que permiten hacer un diagnóstico etiológico del flujo genital (8). Hay además en el ambiente vaginal una serie de microorganismos que no se ponen en evidencia con los métodos diagnósticos de rutina, como son los virus y micoplasmas, que parecen tener un papel patológico en la paciente gineco-obstétrica (9).

Desde el punto de vista clínico-práctico seguimos la clasificación de flujo genital específico e inespecífico; definimos como flujo específico todas aquellas infecciones que producen signos $y$ síntomas específicos por un determinado microorganismo. en esta categoría ubicamos a las Tricomonas vaginales, Neisseria Gonorrea, Coryne bacterium vaginalis y Cándida albicans; y . flujos inespecíficos todos aquellos producidos por una flora mixto-piógena de co- $\cos$ y bacilos grampositivos y gramnegativos, que etiológicamente no producen síntomas ni signos especificos. En estos flujos el grado de pureza vaginal oscila entre III y IV, es decir, con bacilos de Döderlein escasos o ausentes del medio vaginal.

\section{Materiales y métodos}

Se estudiaron 560 pacientes que consultaron por flujo genital, desde dic. 77 hasta agosto 79, 200 de la consulta externa del Hospital Universitario Metropolitano y 360 de la consulta privada.

A las pacientes se les instruyó de no usar duchas vaginales ni tratamiento alguno previo, 72 horas antes del examen. La muestra se tomó antes del tacto, previa aplicación de espéculo estéril, con un aplicador, del fondo de saco posterior de la vagina, del cerviz y cercanías del meato urinario. Con la primera muestra se hacía un frotis, la segunda se introducía en un tubo-rosca estéril con un $\mathrm{ml}$ de solución salina estéril; en el laboratorio del hospital se siguió el siguiente protocolo:

EXAMEN EN FRESCO para la investigación de: leucocitos, tricomonas, levaduduras y pseudomicelios, hematies, bacterias en general.

COLORACION DE GRAM: para investigar bacilos de Döderlein $y$ bacterias en general.

\section{SIEMBRAS EN MEDIOS DE CULTIVOS:}

AGAR SANGRE: Incubado a $37^{\circ} \mathrm{Ceb}$ una atmósfera de $10 \%$ C02 por 24 ó 48 horas para investigar Neisseria Gonorhoeae, bacterias en general y para el aislamiento de Corynebacterium vaginale. 
THAYER MARTIN: para la investigación de Neisseria gonorhoeae, incubado a $37^{\circ} \mathrm{C}$ por 24 ó 48 horas en $10 \%$ de $\mathrm{CO} 2$.

E M B (Eosina azul de metileno) Para el aislamiento de microorganismos entéricos, incubado a $37^{\circ} \mathrm{C}$ por 24 horas aeróbicamente.

SABOURAUD DEXTROSADO: Para cándidas y hongos en general, incubado a $37^{\circ} \mathrm{C}$ por 24 ó 48 horas en aerobiosis.

PARA ANAEROBIOS: Agar sangre: incubado en anaerobiosis (Campana de Gas Park) a $37^{\circ} \mathrm{C}$ por 48 ó 72 horas. Caldo de Tioglicolato: incubado en anaerobiosis (Camapna de Gas Pak) a $37^{\circ} \mathrm{C}$. por 48 ó 72 horas.

Todo el estudio fue elaborado por el mismo personal de microbiología del la- boratorio del Hospital Universitario Metropolitano.

Con los nuevos avances en microbiología se han detectado características generales, diferentes a las registradas anteriormente, de los siguientes microorganismos: denominamos al E. albus como Estafilococo epidermides; al Hemofilus como Corynebacterium vaginalis y a la monilia como Cándida albicans, términos que usaremos en el presente trabajo.

Las pacientes fueron clasificadas, después del tratamiento, de acuerdo con las normas indicadas por el Departamento de Administración de Drogas y Alimentos de los E. U. (F. D. A.): Curadas (curación clínica, examen microscópico negativo y cultivo negativo).

\section{CUADRO No. 1}

\begin{tabular}{rrr}
\hline $\begin{array}{l}\text { EDAD } \\
\text { Años }\end{array}$ & No. de casos & $\%$ \\
\hline-10 & 5 & 0.89 \\
$10-15$ & 9 & 1.60 \\
$16-20$ & 78 & 13.92 \\
$21-25$ & 161 & 28.76 \\
$26-30$ & 129 & 23.04 \\
$31-35$ & 96 & 17.15 \\
$36-40$ & 31 & 5.53 \\
$41-45$ & 25 & 4.46 \\
$46-50$ & 14 & 2.50 \\
+ de 50 & 12 & 2.14 \\
\hline
\end{tabular}

Estado Civil: el $70.18 \%$ correspondió a las casadas y el $29.82 \%$ a las solteras, de las cuales, el $34.73 \%$ eran vírgenes. 
Fracasos (sin cambios en el cuadro clínico y presencia de microorganismos en examen microscópico y cultivo después del tratamiento).

Mejoradas (asintomáticas, pero con evidencia de infección en el examen microscópico o cultivo después del tratamiento).

\section{Resultados:}

En el Cuadro No. 1 se observa que el grupo de edad comprendido entre 16 y 35 años tuvo el mayor porcentaje $(82.87 \%$ ) de consulta por flujo genital. La menor edad fue de 6 años y la mayor de 65 años. Este grupo corresponde a la etapa de mayor actividad sexual.

CUADRO No. 2

\begin{tabular}{lcr}
\hline PARIDAD & No. de casos & \% \\
\hline Nulíparas & 179 & 31.96 \\
Primíparas & 119 & 21.25 \\
Multíparas & 258 & 46.07 \\
Sin datos & 4 & 0.71
\end{tabular}

EI Cuadro No. 2 relacionado con la paridad, registra que el $46.07 \%$ correspondió a multíparas, siguiendo en su orden de frecuencia las nulíparas y primíparas.

CUADRO No. 3

\begin{tabular}{lcr}
\hline SINTOMAS & No. de casos & \% \\
\hline Flujo genital & 251 & 44.82 \\
Flujo genital y prurito & 228 & 40.71 \\
Flujo genital y ardor & 21 & 3.75 \\
Flujo genital, ardor y prurito & 20 & 3.57 \\
Prurito & 9 & 1.61 \\
Flujo genital, prurio y disuria & 7 & 1.25 \\
Flujo genital, prurito, disuria, ardor & 6 & 1.07 \\
Ardor & 6 & 1.07 \\
Asintomáticas & 12 & 2.14 \\
\hline
\end{tabular}

En el Cuadro No. 3 se aprecia que el flujo genital como única manifestación se presentó en el $44.82 \%$, el flujo genital y prurito en el $40.71 \%$, el flujo genital y ardor en el $3.57 \%$. La sintomatología de menor frecuencia fue la asociación de flujo genital, ardor, prurito y disuria. Se halló $2.14 \%$ de pacientes asintomáticas, en las cuales se aisló el Corynebacterium vaginalis en un $33 \%$; en el resto existía flora vaginal inespecífica. 
CUADRO No. 4

\begin{tabular}{lcr}
\hline EXAMEN GINECOLOGICO & No. de casos & $\%$ \\
\hline Vulvitis & 141 & 25.18 \\
Vulvo-vaginitis & 42 & 7.50 \\
Cervicitis & 97 & 17.32 \\
Anexitis & 36 & 6.43 \\
Condilomatosis & 8 & 1.43 \\
Vaginitis & 6 & 1.07 \\
Prolapso genital & 2 & 0.36 \\
Prolapso genital y vulvitis & 1 & 0.18 \\
Pólipo cervical & 4 & 0.72 \\
Bartolinitis & 6 & 1.07 \\
Cisto - rectocele & 217 & 38.75 \\
\hline
\end{tabular}

En el Cuadro No. 4 se registran los datos del examen ginecológico; la vulvitis fue el signo predominante, con una incidencia del $25.18 \%$, siguiendo la cervicitis con $17.32 \%$ y la vulvo-vaginitis
con $7.5 \%$.

CUADRO No. 5

Blanco

Mucoso

Fétido

Espumoso - verdoso

Blanco - espumoso 
(Continuación Cuadro No. 5)

CARACTERES DEL FLUJO

No. de casos

Gris - espumoso

Amarillento

Blanco - grumoso

Parulento

Sero - sanguinolento

En el Cuadro No. 5 se señalan las características del flujo genital que en el $35.53 \%$ fué de aspecto blanquecido, el blanco grumoso (tipo leche cortada) ocupó el $15.36 \%$, el blanco amarillento el $11.78 \%$ siguiendo en su orden el blanco grisoso, el purulento el verdoso espumoso, el blanco espumoso y finamente el sero-sanguinolento.

La cantidad del flujo genital que fue abundante en el $35 \%$, moderado en el $14.46 \%$ y escaso en el 8.39 de los casos, en 236 , casos, $42.15 \%$ no hubo dato.

CUADRO No. 6

\section{ESTUDIO BACTERIOLOGICO}

FLUJO ESPECIFICO: 388 casos $=69.28 \% \quad$ FLUJO INESPECIFICO $=30.72 \%$

C. albicans

$224 \operatorname{casos}=40.00 \%$

Corynebacterium v.

79 casos $=14.10 \%$

Tricomona v.

79 casos $=13.93 \%$

N. gonorheae

$$
10 \text { casos }=2.14 \%
$$

En el Cuadro No. 6 se describe el estudio bacteriológico; hubo una mayor frecuencia del flujo específico $(69.28 \%)$, sobre el inespecífico $(30.72 \%)$.

En el flujo específico el microorganismo de mayor frecuencia fue la C. albicans, con $40 \%$ del total de los casos; siguieron el Corynebacterium vaginalis con un $14.10 \%$; la Tricomona vaginalis con un $13.39 \%$; Neisseria gonorheae con un $2.14 \%$. De los 388 casos de flujo genital específicos la $\mathrm{C}$. albicans tuvo una incidencia del $57.33 \%$ como microorganismo único, y en el $67.86 \%$ asociado a otros gérmenes. 
CUADRO No. 7

CANDIDA ALBICANS

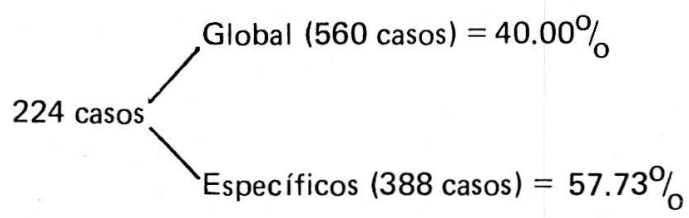

PUROS

72 casos $=32.14 \%$

EN ASOCIACION

152 casos $=67.86 \%$

\section{ASOCIACION MAS FRECUENTE}

No. casos

$\%$

C. albicans + E. epidermides

31

20.39

C. albicans + E. coli

C. albicans +Corynebacterium v.

18

C. albicans + Corynebacterium + E. epidermides

15

C. albicans + Estreptococo v. + E. coli

C. albicans + Corynebacterium v. + E. coli

9

En el Cuadro No. 7 se anota la asociación más frecuente de la C. albicans; en orden de trecuencia la asociación fue $\mathrm{C}$. albicans con E. epidermides, C. albicans con E. Coli, C. albicans con Corynebacterium vaginalis.

CUADRO No. 8

\section{ASOCIACION MENOS FRECUENTE}

No. de casps

C. albicans + Proteus vulgaris

C. albicans + E. coli + Citrobacter

C. albicans + Bacteroides

C. albicans + Difteroides

C. albicans + Epidermis + Mima polimoría

C. albicans + Pseudomonas a. 
(Continuación Cuadro No. 8)

\begin{tabular}{lcc}
\hline ASOCIACION MENOS FRECUENTE & No. de casos & $\%$ \\
\hline C. albicans + E. epidermides + E. coli & 3 & 1.97 \\
C. albicans + Enterobacter sp. & 3 & 1.97 \\
C. albicans + Corynebacterium v. + Enterobacter sp & 2 & 1.31 \\
C. albicans + Pseudomona a. + Aerobacter & 1 & 0.65 \\
C. albicans + Klebsiella & 1 & 0.65 \\
C. albicans + E. dorado & 1 & 0.65 \\
C. albicans + Clostridium & 1 & 0.65 \\
C. albicans + Neisseria g. & 1 & 0.65
\end{tabular}

En el Cuadro No. 8 se discrimina la asociación menos frecuente de C. albicans con diferentes gérmenes.

CUADRO No. 9

CORYNEBACTERIUM VAGINALIS

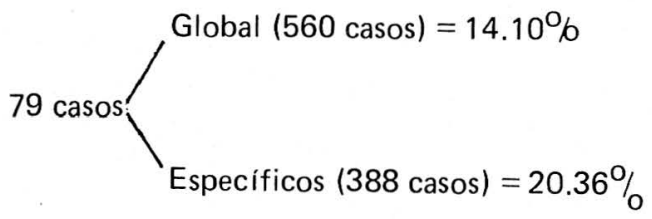

PUROS

35 casos $=44.30 \%$

DE ASOCIACION

$44 \operatorname{casos}=56.70 \%$

En el Cuadro No. 9 el Corynebacterium vaginalis tuvo una incidencia del $20.36 \%$ en el grupo de flujo vaginal específico, en el cual en el $44.30 \%$ se encontró como gérmen único y en el $56.70 \%$ en diferentes asociaciones. 
CUADRO No. 10

CORYNEBACTERIUM VAGINALIS EN ASOCIACION

Corynebacterium v. + Pseudomona a.

Corynebacterium v. + E. epidermides

Corynebacterium v. + E. coli

Corynebacterium v. + C. albicans + E.

epidermides

Corynebacterium v. + Tricomona

Corynebacterium v. + Peptostreptococo sp.

Corynebacterium v. + Difteroides
No. casos

$\%$

6.82

19

43.18

6

13.64

3

6.82

5

11.36

5

11.36

1

En el Cuadro No. 10 se anota la asociación de Corynebacterium vaginales con diferentes gérmenes.

CUADRO No. 11

TRICOMONAS VAGINALIS

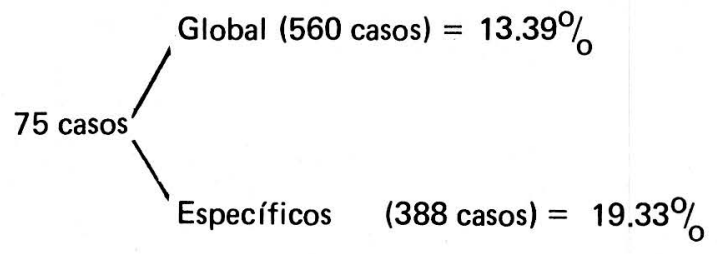

PUROS

$8 \operatorname{casos}=10.67 \%$

EN ASOCIACION

67 casos $=89.33 \%$

En el Cuadro No. 11 la Tricomona tuvo una incidencia del $19.33 \%$ del total de los casos. En el $10.67 \%$ se encontró como gérmen único y asociada en el $89.33 \%$. 
CUADRO No. 12

\begin{tabular}{lcc}
\hline ASOCIACION MAS FRECUENTE & No. casos & $\%$ \\
\hline Tricomona v. + E. epidermides & 17 & 25.37 \\
Tricomona v. + C. albicans + E. epidermides & 11 & 16.42 \\
Tricomona v. + C. albicans + Corynebacterium v. & 5 & 7.46 \\
Tricomona v. + C. albicans & 4 & 5.97 \\
Tricomona v. + Estreptococo fecalis & 5 & 7.46 \\
\hline
\end{tabular}

En el Cuadro No. 12 se indica la asociación más frecuente de Tricomonas con diferentes gérmenes, con E. epidermides fue de $25.37 \%$, C. albicans y E, epidermides fue de $16.42 \%$ más C. albicans, $5.97 \%$ mas Estreptococos fecalis fue de $7.46 \%$

CUADRO No. 13

\begin{tabular}{lcc}
\hline ASOCIACION MENOS FRECUENTE & No. casos & $\%$ \\
\hline Tricomona v. + Proteus vulgaris & 3 & 4.48 \\
Tricomona v. + Corynebacterium v. + E. epidermides & 3 & 4.48 \\
Tricomona v. + Corynebacterium v. & 5 & 7.46 \\
Tricomona v. + Citrobacter f. & 4 & 5.97 \\
Tricomona v. + Enterobacter & 3 & 4.48 \\
Tricomona v. + E. epidermides + E. coli & 2 & 2.98 \\
Tricomona v. + Peptostreptocoso sp. & 2 & 2.98 \\
Tricomona v. + Pseudomona a. & 2 & 2.98 \\
Tricomona v. + Difteroides & 2 & 2.98 \\
Tricomona v. + E. epidermides + Leptotrix v. & 1 & 1.49 \\
Tricomona v. + Veilonella & 1 & 1.49 \\
\hline
\end{tabular}

Asociación menos frecuente de la Tricomona con diferentes gérmenes. 
CUADRO No. 14

\section{NEISSERIA GONORHEAE}

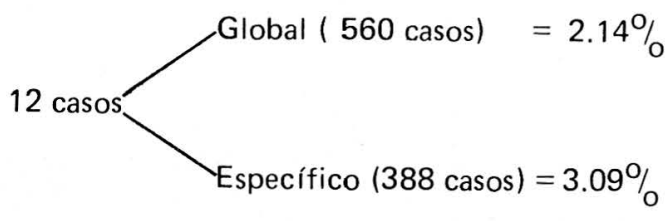

PUROS: $\quad 7$ casos $=58.33 \%$

ASOCIACION 5 casos $=41.67 \%$

La Neisseria gonorheae representó el $3.09 \%$ dentro del grupo de flujo específico. Se halló como microorganismo único en el $58.33 \%$, asociado en el $41.67 \%$. En orden de frecuencia la asociación fue con Corynebacterium v.; Aerobacter, Estreptococo y Mimapolimorfa.

CUADRO No. 15

\section{FLUJO INESPECIFICO}

$$
\begin{aligned}
& 172 \text { casos }=30.72 \% \\
& \text { UN SOLO MICROORGANISMO } \\
& \text { ASOCIACION }
\end{aligned}
$$

\begin{tabular}{lcc}
\hline UN SOLO MICROORGANISMOS & No. casos & $\%$ \\
\hline E. epidermides & 8 & 25.80 \\
Difteroides & 7 & 22.58 \\
E. coli & 5 & 16.13 \\
Proteus vulgaris & 4 & 12.90 \\
Enterobacter sp. & 3 & 9.68 \\
Pseudomona a. & 2 & 6.45 \\
Estreptococo fecalis & 1 & 3.22 \\
Actinomisis sp. & 1 & 3.22 \\
\hline
\end{tabular}

En el grupo de pacientes con flora inespecífica se aisló sólo un microorganismo en $18.02 \%$ de los casos y en el $81.97 \%$, flora mixta de asociación. En el Cuadro No. 15 vemos que las bacterias únicas más frecuentemente encontradas son E. epidermides, Difteroides, E. coli y Proteus vulgaris. 
CUADRO No. 16

\begin{tabular}{lcr}
\hline FLORA DE ASOCIACION & No. casos & \% \\
\hline E. epidermides + E. coli & 56 & 39.72 \\
Difteroides + E. coli & 29 & 20.56 \\
Difteroides + E. epidermides & 24 & 17.02 \\
Difteroides + Enterococo & 15 & 10.64 \\
E. epidermides + Enterococo & 13 & 9.22 \\
Difteroides + Pseudomonas a. & 4 & 2.84 \\
\hline
\end{tabular}

En el Cuadro No. 16 aparece la asociación de bacterias encontradas con mayor frecuencia. En primer lugar E. epidermides más E. coli con un $39.72 \%$; luego Difteroides más E. coli con un $20.56 \%$ Difteroides más E. epidermides con un $17.02 \%$, Difteroides más Enterococo con $10.64 \%$, E. epidermides más Enterococo con un $9.22 \%$ v Difteroides más Pseudomonas con un $2.84 \%$.

Se hizo control bacteriológico a los 7 y 30 días después del tratamiento en 332 casos y sólo control clínico en 228 casos.

CUADRO No. 17

\begin{tabular}{lrl}
\hline PACIENTES EMBARAZADAS : & 67 casos $=$ & $11.96 \%$ \\
PACIENTES NO EMBARAZADAS : & 493 casos $=$ & $88.04 \%$ \\
Planificaban la familia : & 125 casos $=$ & $25.35 \%$ \\
No planificaban la familia : & 368 casos $=$ & $74.65 \%$ \\
CONTRACEPTIVOS HORMONALES : & 70 casos $=$ & $56.00 \%$ \\
D. I. U. & 36 casos $=$ & $26.80 \%$ \\
OTROS METODOS : & 15 casos $=$ & $15.20 \%$ \\
\hline
\end{tabular}

En el presente estudio se registraron 67 pacientes embarazadas $(11.96 \%$ ) y $493(88.04 \%$ ) que no lo estaban; de éstas $125(25.53 \%)$ planificaban y $368(74.65 \%)$ no. Con contraceptivos hormonales planificaban 70 pacientes $(56 \%)$, con D.I.U. $36(28.8 \%)$ V con otros métodos $19(15.2 \%)$. 
CUADRO No. 18

\begin{tabular}{lll}
\hline CURACION & MEJORIA & FRACASO \\
265 casos $=47.30 \%$ & 230 casos $=4.1 .07 \%$ & 65 casos $=11.60 \%$ \\
\hline
\end{tabular}

Del total de 560 pacientes tratadas, $265(47.30 \%)$ mostraron curación, 230 mejoría clínica $(41.07 \%)$; en 65 pacientes fracaso el tratamiento $(11.63 \%)$.

CUADRO No. 19

\begin{tabular}{lc}
\hline MICROORGANISMO & FRACASO \\
\hline C. albicans & $13.85 \%$ \\
C. albicans + Corynebacterium v. & $15.38 \%$ \\
C. albicans + E. coli & $6.15 \%$ \\
Corynebacterium v. & $10.77 \%$ \\
Tricomona & $6.66 \%$ \\
Gonococo & $8.33 \%$ \\
\hline
\end{tabular}

Correspondió a la C. albicans como gérmen único el $13.85 \%$ de fracaso en el tratamiento; a la asociación C. albicans con Corynebacterium el $15.38 \%$, C. albicans con E. coli el $6.15 \%$ y al Corynebacterium $v$. como bacteria única el $10.77 \%$. A las tricomonas correspondió el $6.66 \%$ de fracasos $y$ al gonococo el $8.33 \%$

CUADRO No. 20

\begin{tabular}{lccrr}
\hline DROGA & No. Casos & CURACION & MEJORIA & FRACASO \\
\hline Miconazol * $^{*}$ & 68 & $47=69.11 \%$ & $19=27.94 \%$ & $2=2.94 \%$ \\
Nistatina $^{*}$ & 44 & $37=84.10 \%$ & $3=6.82 \%$ & $4=9.08 \%$ \\
Clotrimazol $^{* *}$ & 33 & $25=75.76 \%$ & $4=12.12 \%$ & $4=12.12 \%$ \\
Violeta de genciana $2 \%$ & 79 & $36=45.57 \%$ & $33=41.77 \%$ & $10=12.66 \%$
\end{tabular}

* Gyno Daktarin

** Micostatin

*** Canesten 
En los cuadros siguientes se discriminan los resultados de acuerdo al microorganismo y a los medicamentos utilizados. En el Cuadro No. 20 se observa la acción de los diferentes medicamentos sobre la C. albicans; con el Micanozol la curación y mejoría fue del $97.05 \%$ y el fracaso del $2.94 \%$; con la Nistatina la curación y mejoría fue del $90.92 \%$ y el fracaso del $9.08 \%$; con el Clotrimazol la $^{\circ}$ curación y mejoría fue de $87.88 \%$ y el fracaso de $12.12 \%$; con la violeta de genciana el $2 \%$ cura ción, mejoría de $87.34 \%$ y fracaso de $12.66 \%$. Efectos collaterales: $1 \%$ de vulvitis por la violeta y $0.5 \%$ de aumento del ardor $y$ prurito vulvovaginal.

CUADRO No. 21

\begin{tabular}{lcrcc}
\hline DROGA & No. Casos & CURACION & MEJORIA & FRACASO \\
\hline Nimorazol $^{*}$ & 45 & $33=73.33 \%$ & $10=22.22 \%$ & $2=4.44 \%$ \\
Metronidazol $^{*}$ & 25 & $16=64.00 \%$ & $7=28.00 \%$ & $2=8.00 \%$ \\
Otros & 5 & $2=40.00 \%$ & $2=40.00 \%$ & $1=20.00 \%$ \\
\hline
\end{tabular}

* Naxogin oral

* Flagyl

En el Cuadro No. 21 se aprecia que para la Tricomona las drogas que ofrecieron el mayor porcentaje de curación y mejoría fueron el Nimorazol con $95.56 \%$

$y$ el Metronidazol con el $92 \%$.

CUADRO No. 22

\begin{tabular}{lccll}
\hline DROGA & No. Casos & CURACION & MEJORIA & FRACASO \\
\hline $\begin{array}{l}\text { Sulfisoxasol * } \\
\text { Cloranfenicol + Miralact }\end{array}$ & 21 & $10=47.61 \%$ & $10=47.61 \%$ & $1=4.77 \%$ \\
+ Clopanona ${ }^{* *}$ & 38 & $15=39.47 \%$ & $20=52.63 \%$ & $3=7.89 \%$ \\
Mitrofurazona ${ }^{* *}$ & 18 & $2=11.11 \%$ & $12=66.67 \%$ & $4=22.22 \%$ \\
Otros & 2 & $2=100 \%$ & & \\
\hline
\end{tabular}

\section{* Gantrisin crema vaginal}

** Polivaginal Ov.

*** Furacin ov.

En el Cuadro No. 22 se observa la acción de diversos medicamentos sobre el Corynebacterium v con el Sulfisoxazol se obtuvo curación y mejoría en el $95.22 \%$ y fracaso en $4.77 \%$ de los casos. Con la asociación de cloranfenicol más Miralat más Clopanona se obtuvo curación y mejoría del $92.10 \%$ y fracaso de $7.89 \%$. Con la Nitrofurazona se obtuvo una curación del $77.78 \%$ y fracaso, de $22.22 \%$ \%

Para la Neisseria gonorheae sólo se usó el Amoxal con un fracaso del $8.33 \%$. 
CUADRO No. 23

\begin{tabular}{lcrrr}
\hline DROGA & No. Casos & CURACION & MEJORIA & FRACASO \\
\hline $\begin{array}{l}\text { Cloranfenicol + Miralact } \\
\text { + Clopanona }\end{array}$ & 84 & $14=16.67 \%$ & $60=71.42 \%$ & $10=11.90 \%$ \\
Tetraciclina +Anfotericina $^{*} 56$ & $12=21.42 \%$ & $35=62.50 \%$ & $9=16.07 \%$ \\
Nitrofurazona & 32 & $6=18.75 \%$ & $15=46.88 \%$ & $11=34.34 \%$ \\
\hline
\end{tabular}

Talseclin

En el Cuadro No. 23 se indican las drogas utilizadas en el flujo genital inespecífico. La asociación Cloranfenicol más Miralact Clopanona se utilizó en 84 casos con una incidencia de curación y mejoría del $88.09 \%$ y con un fracaso del $11.90 \%$. La asociación de Tetraciclina más Anfotericina tuvo una incidencia de curación y mejoría de $83.92 \%$ y de fracaso de $16.07 \%$; la Nitrofurazona una incidencia de fracaso de $34.37 \%$.

\section{DOSIS UTILIZADA:}

Candidiasis: Miconazol crema al $1 \%$, durante 14 noches. Clotrimazol: un óvulo por 6 noches y pomada externa en la mujer y en el hombre durante un mes. Violeta de genciana al $2 \%$ : una embrocación cada 3 días hasta completar 4 embrocaciones, en ocasiones asociada a la Nistatina oral $500.000 \cup 3$ veces al día durante 7 días. Tricomonas: Nimorazol: un óvulo durante 6 noches y 4 tabletas de $\mathbf{5 0 0}$ mgrs por vía oral en una sola dosis, tanto a la mujer como al hombre. Metronidazol: un óvulo durante 10 noches y dos tabletas de $250 \mathrm{mg}$ diarias durante 10 días, por vía oral.

Corynebacterium vaginalis: Sulfisoxazol: un aplicador cada noche durante 12 días, asociado a Tetraciclina oral $250 \mathrm{mg}$. o Ampicilina $500 \mathrm{mgrs}$, cada 6 horas durante 4 días, o Talseclín 15 óvulos para aplicar uno cada 12 horas. La asociación Cloranfenicol más Miralact más Clopanona; un óvulo diario durante 12 noches. Nitrofurazona: un óvulo por 6 noches más Ampicilina oral 2 mgrs. diarios por 4 días.

CUADRO No. 24

\section{7 casos}

Corynebacterium v.

C. albicans

\section{CONTRACEPTIVOS ORALES}

C. albicans en asociación

E. epidermides

$$
7 \text { casos }=10.45 \%
$$

$42.26 \%$

$2.99 \%$

$20.00 \%$

$57.15 \%$

$21.43 \%$ 
Neisseria gonorheae: se utilizó el Amoxal a razon de 3 gramos, en una sola dosis. Para los flujos inespecíficos se utilizaron dosis según esquema anterior. En los flujos específicos con gérmenes de asociación se hacía tratamiento al más patógeno y secundariamente al asociado según la pauta
anterior.

En las prcientes embarazadas el tratamiento en general fracasó en el $10.45 \%$; este fracaso correspondió al Corynebacterium v. en un $42.26 \%$ y a la C. albicans en un $2.99 \%$. En las pacientes que tomaban anticonceptivos orales hubo un $20 \%$ de fracaso en el tratamiento y el gérmen aislado en estos casos fue la C. albicans $y$ sus asociaciones en un $57.15 \%$, seguido del $E$. epidermides en un $21.43 \%$ \%

\section{Comentarios}

En las últimas décadas se registra que la edad correspondiente a la mayor actividad sexual determina una alta incidencia de flujo genital, cuya causa se origina en la libertad sexual que rige hoy el uso de contraceptivos hormonales que motivan un cambio en el hábito sexual, desde el aumento de su frecuencia hasta la promiscuidad. Esta situación se refleja también en el estado civil, pues las casadas registran una mayor frecuencia de flujo genital que las solteras (10). La. multiparidad es un factor que conlleva una serie de trastornos de la integridad genital (lesiones cervicales $y$ desgarros vaginoperineales) que predisponen a una mayor frecuencia del flujo genital (11), como se demuestran en este estudio.

Síntomas predominantes del flujo genital fueron la asociación de prurito, ardor $y$ vulvovaginitis $(11,12)$. El flujo geni tal blanco grumoso (tipo "leche cortada") fue el de mayor predominio, obedeciendo a que la mayor frecuencia también correspondió a la $\mathrm{C}$. albicans, cuyo flujo tiene estas caracter ísticas $(13,14,15)$.

El flujo genital de mayor incidencia fue el de tipo específico; dentro de este tipo correspondió a la C. albicans la mayor frecuencia, seguida del Corynebacterium v. y de la Tricomona. La mayor aso- ciación de la C. albicans y la Tricomona fue con el E. epidermides; no encontramos la asociación de estos microorganismos con la Leptotrix y con los Bacteroides informado por otros autores (16).

La incidencia de Gonorrea registrada en nuestro estudio es baja en relación con las cifras dadas por otros autores $(17,18)$.

En el flujo genital inespecífico la flora mixta de asociación fue la más frecuente. En el $18 \%$ de los casos de flujo inespecífico se aisló un sólo gérmen, debido posiblemente a que hay otros tipos de microorganismos como los virus y micoplasmas que requieren medios $y$ técnicas muy especializados para su deteción.

En las pacientes embarazadas encontramos una incidencia de Candidiasis de $49.25 \%$, cifra alta en relación con otros autores $(19,18,11,10,13)$. La incidencia de Tricomonas está más o menos de acuerdo con lo evidenciado por otros investigadores $(18,20,21)$; en cambio la incidencia de gonococo es baja en comparación con otros estudios.

La presencia de micosis vaginal durante el embarazo representa un riesgo potencial patógeno para la madre y el hijo, ya que se han reportado casos de infección tanto en el feto como en la placenta (22). Para el recién nacido el riesgo es ma- 
yor ya que se ha registrado un $27.2 \%$ de infección al quinto día de nacido (19) manifestándose por estados catarrales transitorios, o en forma de micosis oral o urogenital que pueden llegar a una neumonía o a una sepsis micótica mortal. Por lo tanto, queremos resaltar que la presencia de cándida o levadura en flujo genital de la mujer embarazada debe tratarse. No está de más insistir en la importancia de la presencia de los otros microorganismos de tipo específico durante el embarazo, los cuales deben ser tratados por el riesgo potencial patógeno, que tanto para la madre como al feto cada uno de ellos conlleva.

El factor predisponente de la candidiasis en el embarazo se debe a la falta de células superficiales debido a los altos niveles de progesterona que hacen más vulnerable la mucosa vaginal a las infecciones; esta misma causa es valedera para las pacientes que usan contraceptivos hormonales. En el presente estudio registramos una alta incidencia de candidiasis en las pacientes usuarias de contraceptivos hormonales.

Durante el embarazo aumenta el riesgo de desarrollar una infección gonocócica diseminada, lo que se asocia a un riesgo de pérdida fetal o de un niño de bajo peso al nacer, además de las clásicas conjuntivitis del nacimiento $(23,24,25)$.

Algunos autores han registrado una alta incidencia de fiebre en el puerperio en mujeres infectadas por Corynebacterium v. (26), como también infecciones en el recién nacido (27). Observamos una mayor infección por Corynebacterium v. en las embarazadas que en las no embarazadas, dato este que está de acuerdo con otros autores (28).
La mayor incidencia de fracaso en el tratamiento del Corynebacterium v. posiblemente fue debida a no tratar al esposo, ya que es aceptada como una enfermedad venérea transmisible $(7,22)$.

\section{Resumen}

Presentamos un estudio del flujo vaginal de $\mathbf{5 6 0}$ pacientes, tanto privadas como hospitalarias, realizado durante 21 meses, en el período comprendido entre dic/77 y agosto/79; la toma de muestras para frotis directo y cultivo, fue analizado en el laboratorio clínico del Hospital Universitario Metropolitano.

Se presentan los resultados obtenidos y el análisis en relación con edad, paridad, sintomatología, hallazgos al examen clínico y características del flujo genital; resultados del estudio bacteriológico, flujos específicos e inespecíficos y resultados del tratamiento.

Concluimos observando una mayor incidencia de flujo en la etapa de actividad sexual y en mujeres casadas; alta incidencia de candidiasis en gestación y el riesgo potencial para el producto, tanto por ella como por el Corynebacterium v.

\section{GENITAL FLUX}

\section{Summary}

We present a genital flux study in $\mathbf{5 6 0}$ patients, both private and hospitalaries carried out during a 21 months period from December 1977 through August 1979. 
The sample intake for direct smear and culture was analyzed at the clinical laboratory of the Metropolitan University Hospital.

We show the results achieved and the analysis regarding age, parity, symptomatology, discoveries in the clinical examination and typical of the genital flux, as well as the results of the bacteriological study, the specific and unspecific fluxes and the results of the treatment.

In conclusion, we observed a higher flux incidence in the sexual activity stage and in married women; a high candidiasis incidence in gestation and the potencial risk for the product, both for her and for the corynebacterium.

\section{Bibliografía}

1. ACOSTA BENDEK E., DUVA PALACIO J., VASQUEZ MACIAS N.: Estudio bacteriológico y citológico de la vagina de la recién nacida. Rev. Obst. y Ginec. 25:255, 1974.

2. DURAN VELASCO F., REY REY P.: Flujos genitales. Rev. Col. Obst. y Ginec. 11: 61, 1960.

3. CARDONA P. N.: La micosis en las leucorreas. Rev. Col. Obst. y Ginec. 11: $130,1960$.

4. HUFFMAN JOHN.: Ginecología en la infancia $y$ en la adolescencia. Salvat Editores. Barcelona. 1971.

5. SCHNELL J. D.: Citología y microbiología de la vagina. S. KanopBasel München. 1975.
6. GARDNER H. L. y COLS.: Benign diseases of the vulva and vagina. C. V. Company Mosby. Saint Louis. 1969.

7. WIESNER P. J. y COL.: Venereal disease in obstetrics and gynecology Clinical Obstetrics and Ginecology. 18: 31, 1975.

8. BURROWS W.: Tratado de Microbiología. Interamericana S. A. México. 1969.

9. HAMMERSCNLAG M.: Anaerobic microflora of the vagina in children. Am. J. Obst. \& Gynec. 131: 853, 1978.

10. ALVAREZ BRAVO A.: Tratamiento de la vulvo-vaginitis por cándida con Clotrimazol durante 3 días. REv. Mex. Obst. y Ginec. 43: 379, 1978.

11. FERNANDEZ DEL CASTILLO C. y COL.: Tratamiento con Clotrimazol de la infestación genital femenina por C. albicans. Rev. Méx. Obst. y Ginec. 43: 299, 1978.

12. SOMOGY L., y COL.: Experiencia con el Haloprogin en el tratamiento de las candidiasis vaginales. Rev. Venezolana Obst. y Ginec. 38: 57, 1978.

13. ACOSTA BENDEK E.: Tratamiento del flujo genital. Rev. Col. Obst. y Ginec. 11: 130, 1960.

14. MORENO J., y Col.: Clotrimazol en el tratamiento de la candidiasis vulvovaginal. Rev. Venezolana Obst. y Ginec. 37: 261, 1977. 
15. ROBERTSON W. H.: Vulvovaginal candidiasis treated with Clotrimazole cream in seven days compared with fourteen - days treatment with miconazole cream. Am. J. Obst. \& Gynec. 132: 321, 1978.

16. SYVERSON R. E. y Col. Celular an humoral inmune status in women with chronic candica vaginitis. Am. J. Obst. \& Gynec. 134: 624, 1979.

17. DANS P.: Gonococcal anogenital infeccion. Clinical Obst. \& Gynec. 18: 103, 1975.

18. MORENO J. y Cols.: Parasitosis genital en gestantes $y$ no gestantes. Rev. Venezolana Obst. y Ginec. 38: 185, 1978.

19. SCHNELL J. D.: Clotrimazol. Su importancia en el profilaxis de la micosis durante el embarazo. Experiencias y Perspectivas. Rev. Bayer. 1975.

20. ROVINSKY J. y Col.: Complicaciones médicas, quirúrgicas y ginecológicas en el embarazo. Interamericana S. A. 1967.
21. FONNEGRA M. A. y Cols. Tratamiento de la tricomoniasis genital con un nuevo quimioterápico: la Nitroinidazine. Rev. Col. Obst. y Ginec. 21: 141, 1970.

22. WINNER H. I.: Symposium on candida infections. $E$ \& S Livingstone Ltd. 1966.

23. EDMUNDS P.: Haemophilus vaginalis. Its association with puerperal pyrexia and leucorrhoea. J. Obstet Gynecol Br. Commonw. 66: 917 1959.

24. PLATT M. S.: Neonatal Hemofilus vaginalis (Corynebacterium v.) infection. Clin. Pediatr. 10: 513, 1971.

25. LEWIS J. y Col. Corynebacterium vaginale. Vaginitis in pregnant women. Am. J. Clin. Pathol. 56: 58, 1971.

26. VERGARA TAMARA R.: EI hemofilus vaginales como agente etiológico de algunas de las llamadas vaginitis no específicas. Rev. Col. Obst. y Ginec. 21: 123, 1960. 